\title{
THE HEMATOLOGICAL REPRESENTATION OF PREGNANT WOMAN IN THE THIRD TRIMESTER WITH CONFIRMED COVID-19 POSITIVE IN RSUD DR. SOETOMO
}

\author{
Sylla Nur Samsiah ${ }^{1}$, Lestari Sudaryanti ${ }^{2 *}$, Dwi Izzati Budiono ${ }^{1,3}$ \\ ${ }^{1}$ Department of Midwifery Education, Faculty of Medicine University Airlangga 60132, Surabaya, East java, Indonesia \\ ${ }^{2}$ Department public health, Faculty of Medicine University Airlangga 60132, Surabaya, East Java, Indonesia \\ ${ }^{2}$ lestari.sudaryanti@ vokasi.unair.ac.id
}

\begin{abstract}
Background The world is faced with the reality of preparing to live side by side with COVID-19. During pregnancy, there are physiological and mechanical changes in the body that can have an impact on the ability of the immune system to decrease. Laboratory tests such as hematology examinations play an important role in screening patients who have the potential to lead to COVID-19. The purpose of the study was to describe the results of blood tests in pregnant women in the third trimester who were confirmed positive for Covid-19. Methods: type of descriptive research with a retrospective study, using secondary data in the form of medical record status. The sampling technique used total sampling with the results of 102 3rd-trimester pregnant women with positive Covid-19 RT-PCR test results. The inclusion criteria were data on pregnant women in the third trimester who were confirmed positive for Covid-19 which were recorded in the medical record at the SMF Obstetrics and Gynecology inpatient unit, RSUD Dr. Soetomo. Results: 56.9\% low basophil value; 71.6\% low eosinophils; $54.9 \%$ normal hemoglobin; $94.1 \%$ low lymphocyte; $68.6 \%$ of normal monofil; $94.1 \%$ high neutrophil; $90.2 \%$ normal platelets; white blood cell count (WBC) $77.5 \%$ high. Conclusion The haematological representation shows a decrease in basophil, eosinophil, lymphocytes or also known as lymphopenia. More than half of the normal monocyte, platelet, and hemoglobin values, an increase in neutrophil or also called neutrophilia and an increase in the leukocyte count or WBC value indicate leukocytosis.
\end{abstract}

Keywords: Covid-19; pregnant women; blood lab test

\section{Introduction}

December 2019 marked the beginning of the identification of a new coronavirus disease (2019-nCoV) that caused the first reported acute respiratory syndrome epidemic in Wuhan, China [1]. The disease caused by the new coronavirus is then referred to as Corona-virus disease-2019 (COVID-19). The World Health Organization (WHO) declared the Coronavirus 2019 (COVID-19) as a public health emergency of international concern on January 30, 2022, which has a high global risk [2]. The prevalence of COVID-19 continues to increase. Case reports in Indonesia based on the COVID-19 Task Force until November 23, 2021 
recorded 4,253,992 confirmed cases, 4,102,232 recovered cases and 143,753 deaths [3]. The world is faced with the reality to prepare for coexistence with COVID-19.

During pregnancy, physiological and mechanical changes occur in the body which can have an impact on the decrease in the ability of the immune system [4][5]. A decrease in the immune system can lead to an increased risk for infection in general [6]. Currently, there is a lot of data about Covid-19, but information about pregnancy with Covid-19 is still limited [5]

Laboratory tests such as hematology examinations play an important role in screening patients who have the potential to lead to COVID-19. Especially in areas that do not yet have RT-PCR facilities, can identify patients at risk of complications and determine treatment interventions or medical actions in patients who have been confirmed positive for COVID-19. In severe cases of Covid-19, there was an increase in the number of leukocytes and the neutrophil-lymphocyte ratio, a decrease in the number of lymphocytes, and a decrease in the percentage of monocytes, eosinophils, and basophils [7]. In addition, thrombotic complications in patients with COVID-19 are common and contribute to organ failure and death, so it is important to examine and monitor platelets [8].

The group of pregnant women in the third trimester with confirmed COVID-19 is the main target in the study because pregnancy conditions are very susceptible to infection [6]. This study was conducted to know the description of the results of blood tests in the 3rd trimester of pregnant women who were confirmed positive for Covid-19. Various changes in hematological parameters can provide information to help identify COVID-19 patients, patients who are at risk of complications and can determine the action/treatment so that it is very important information during this pandemic, and the current COVID-19 data on pregnant women is still lacking.

\section{Method}

The study is descriptive with a retrospective approach, which uses secondary data in the form of medical records in the 3rd trimester pregnant women who are confirmed positive for Covid-19 at Dr. Soetomo Surabaya in the period March 2020 - August 2021 at the SMF Obstetrics and Gynecology Inpatient Installation at Dr. Soetomo, Surabaya, Indonesia.

The sampling technique used total sampling with the results of 102 3rd-trimester pregnant women with positive Covid-19 RT-PCR test results. The inclusion criteria were data on pregnant women in the third trimester who were confirmed positive for Covid-19 which were recorded in the medical record at the SMF Obstetrics and Gynecology inpatient unit, Dr. Soetomo Hospital. Patients with medical record data accompanied by the attachment of hematological examination results (basophils, eosinophils, hemoglobin, lymphocytes, monocytes, neutrophils, platelets, leukocyte count, or WBC). This research was approved by the research ethics committee of RSUD Dr. Soetomo (0531/LOE/301.4.2/VII/2021).

\section{Result}

Our research was carried out at the SMF Obstetrics and Gynecology Inpatient Installation, Dr. Soetomo, Surabaya, Indonesia. There were 102 samples of 3rd-trimester pregnant women who were confirmed positive for Covid-19 by RT-PCR examination from March 2020 until August 2021. 
Table 1. characteristics of pregnant women trimester 3

\begin{tabular}{lll}
\hline Variable & $\mathrm{N}$ & $\%$ \\
\hline Age of pregnant women (years) - Average & $30.25( \pm 6.1)$ & \\
(SD*) & & \\
Age of pregnant women & 79 & 77.5 \\
$\quad<35$ & 23 & 22.5 \\
$>35$ & & \\
Gestasional age & 39 & 38.2 \\
$<37$ weeks & 63 & 61.8 \\
$>37$ weeks & & \\
Symptoms of Covid-19 & 79 & 77.5 \\
$\quad$ Asymptomatic & 23 & 22.5 \\
$\quad$ Symptomatic & & \\
Type of delivery & 41 & 40.2 \\
$\quad$ Pervaginam & 61 & 59.8 \\
$\quad$ Sectio caesarea & & \\
Comorbid & 59 & 57.8 \\
$\quad$ With comorbid & 43 & 42.2 \\
$\quad$ No comorbid & & 69.6 \\
Thoracic photo & 71 & 30.4 \\
$\quad$ Cor and pulmo within normal & 31 & \\
Bilateral pneumonia & & \\
\hline SD = standard deviation & & \\
\hline
\end{tabular}

Table 1 shows that the average age of pregnant women in the third trimester is 30.25 (6.1); the majority are less than 35 years old; the majority of pregnant women in the third trimester give birth at more than 37 weeks of gestation; the majority do not have clinical symptoms of Covid-19 or are asymptomatic; more than half had a section caesarea delivery; more than half of 3rd-trimester pregnant women with comorbidities; the majority had chest thorax results, namely cast and lugs within normal limits.

Table 2. overview of hematoma test results pregnant women trimester $3^{\text {rd }}$ with positive RT-PCR test results Covid-19

\begin{tabular}{lll}
\hline Variable & Average (SD*) & $\mathrm{N}(\%)$ \\
\hline Basophil \% & $0.256( \pm 0.125)$ & \\
\hline Low $<0.3$ & & $58(56.9)$ \\
\hline Normal 0.3 - 1.4 & & $44(43.1)$ \\
\hline Eosinophile \% & $0.658( \pm 1.302$ & \\
\hline Low 0.6 & & $73(71.6)$ \\
\hline Normal $0.6-5.4$ & $26(25.5)$ \\
\hline Hight $>5.4$ & $11.098( \pm 1.804)$ & $3(2.9)$ \\
\hline Hemoglobin g/dL & \\
\hline Low $<11$ & & $44(43.1)$
\end{tabular}




\begin{tabular}{|c|c|c|}
\hline Normal $11-14.7$ & & $56(54.9)$ \\
\hline Hight $>14.7$ & & $2(2)$ \\
\hline Lymphocytes \% & $11.67( \pm 7.134)$ & \\
\hline Low $<23.1$ & & $96(94.1)$ \\
\hline Normal $23.2-49.9$ & & $5(4.9)$ \\
\hline Hight $>49.9$ & & $1(1)$ \\
\hline Monocytes \% & $5.223( \pm 2.518)$ & \\
\hline Low $<4.3$ & & $30(29.4)$ \\
\hline Normal $4.3-10$ & & $70(68.6)$ \\
\hline Hight $>10$ & & $2(2)$ \\
\hline Neutrophil \% & $82.173( \pm 9.69)$ & \\
\hline Low 39.8 & & $1(1)$ \\
\hline Normal $39.8-70.5$ & & $5(4.9)$ \\
\hline Hight $>70.5$ & & $96(94.1)$ \\
\hline Platelets $103 / \mathrm{uL}$ & $294.4( \pm 9.617)$ & \\
\hline Low $<150$ & & $3(2.9)$ \\
\hline Normal $150-450$ & & $92(90.2)$ \\
\hline Hight $>450$ & & $7(6.9)$ \\
\hline $\mathrm{WBC}^{*} 10^{3} / \mathrm{uL}$ & $14.53( \pm 1.578)$ & \\
\hline Normal $3.37-10$ & & $23(22.5)$ \\
\hline Hight $>10$ & & $79(77.5)$ \\
\hline
\end{tabular}

Table 2 shows the basophil value of 58 patients $(56.9 \%)$ decreased, 44 patients $(43.1 \%)$ were in normal condition, the average basophil value was $0.256(0.125) \%$. Eosinophil values in 73 patients $(71.6 \%)$ were low, 26 patients $(25.5 \%)$ were normal and 3 patients $(2.9 \%)$ were high, the average eosinophil value was $0.658(1.302) \%$. HGB or hemoglobin values of more than half of pregnant women in the third trimester, 56 $(54.9 \%)$ were normal, 44 patients $(43.1 \%)$ were low and only 2 patients $(2 \%)$ were high, the average hemoglobin value was $11,098(1,804) \mathrm{g} / \mathrm{dL}$. The majority of pregnant women in the third trimester had low lymphocyte values 96 patients (94.1\%), 5 patients (4.9) were normal, and only 1 patient (1\%) was high, the average lymphocyte value was $11.67(7,134) \%$. The majority of monocyte values in 70 patients $(68.6 \%)$ were normal, 30 patients $(29.4 \%)$ were low, and only 2 patients $(2 \%)$ were high, the average monocyte value was $5.223(2,518) \%$. The neutrophil value of 96 patients $(94.1 \%)$ was high, 5 patients $(4.9 \%)$ were normal, and only 1 patient $(1 \%)$ was low, the average neutrophil value was $82.173(9.69) \%$. Platelet values of 92 patients (90.2\%) were normal, 7 patients $(6.9 \%)$ were high, and only 3 patients $(2.9 \%)$ were low, the average platelet value was $294.4(9,617)$ X $103 / \mu \mathrm{L}$. White blood cell count (WBC) values in 79 patients $(77.5 \%)$ were high and $23(22.5 \%)$ normal, the mean WBC value was $14.53(1.578) \times 103 / \mu \mathrm{L}$ (see table 2).

\section{Discussion}

The study is descriptive with a retrospective approach, which uses secondary data in the form of medical records in the 3rd trimester pregnant women who are confirmed positive for Covid-19 at Dr. Soetomo Surabaya in the period March 2020 - August 2021 at the SMF Obstetrics and Gynecology Inpatient Installation at Dr. Soetomo, Surabaya, Indonesia. 
From the results of the study through the collection of hematological data on pregnant women who were confirmed positive for Covid-19 from March 2020 to August 2021 at the SMF Obstetrics and Gynecology Inpatient Installation, 102 pregnant women met the inclusion criteria. The basophil count of 58 pregnant women $(56.9 \%$ ) was low and 44 pregnant women $(43.1 \%)$ were within normal limits. This is in line with research conducted by Susilo et al which stated that a decrease in basophils was found in patients with Covid19 cases weight [7]. Sun et al. found a significant decrease in lymphocytes, eosinophils, and basophils [9].

The eosinophil value obtained in 73 pregnant women (71.6\%) was low or decreased, this is in accordance with a previous study conducted by Sun et al on 116 Covid-19 patients, namely routine peripheral blood examinations that the number of eosinophils was below the normal number [9]. Decreased eosinophils may describe severe cases of Covid-19 [7].

Our study showed hemoglobin values of $54.9 \%$ normal and $43.1 \%$ low or decreased. The results of laboratory tests conducted by lipi and plebani (2021) reported that hemoglobin had changed in patients with confirmed Covid-19 [10]. Patients with Covid-19 may develop anemia [11] [12]. The cause of anemia in Covid-19 patients occurs due to the interaction between the SARS-Cov-2 virus and hemoglobin molecules through CD26, CD147, and other receptors located on erythrocytes which will induce hemoglobinopathy thereby inducing hemolysis and hemoglobin dysfunction. In sepsis, there is a decrease in the number of hematocrit, erythrocytes, and hemoglobin [12]. In patients with severe COVID-19, hemoglobin levels were significantly lower than in patients with mild COVID-19 [13].

The lymphocyte values in the study through medical record data were 96 pregnant women in the third trimester $(94.1 \%)$ who were low or experienced a decrease (lymphopenia). This result is in line with a previous study conducted on pregnant women who found $45.5 \%$ had lymphocytopenia [14]. This result is also in line with a study conducted in China which found $83.2 \%$ of patients with lymphocytopenia, $36.2 \%$ of thrombocytopenia and $36.2 \%$ of leukocytopenia [15]. The lymphocyte value can determine the severity of Covid-19, the number of lymphocytes or the immune system decreases as the severity of Covid-19 increases [15].

The last type of leukocyte studied, namely monocytes, showed results in 70 pregnant women $(68.6 \%)$ normal and 30 pregnant women $(29.4 \%)$ decreased. Decreased monocytes are often caused by the use of glucocorticoids, stress, aplastic anemia. During pregnancy pregnant women have normal monocyte values [16]. A decrease in monocytes was found in patients with severe Covid-19 cases [7].

In our study, almost all neutrophil values of 96 pregnant women $(94.1 \%)$ were high and 5 pregnant women $(4.9 \%)$ were normal. This is in accordance with a systematic review conducted by Chamseddine et al which stated an increase in neutrophils or called neutrophilia [17]. Susilo et a stated that in patients with severe Covid-19 cases there was an increase in the number of leukocytes and neutrophil-lymphocyte ratio [7]. Neutrophilia can indicate viral infections, parasites, bleeding to myeloproliferative disorders [18].

In our study, the platelet count was $90.2 \%$ normal. The results are consistent with a previous study conducted on 11 pregnant and 25 non-pregnant women at a University-affiliated tertiary medical center that found normal values for hemoglobin, WBC, and platelets [14]. During pregnancy there can be a significant decrease in platelets because the uterine wall is developing to compensate for fetal growth, lacerations in blood vessels can occur, causing massive bleeding. Thrombocytopenia can occur in normal pregnancies despite not being infected with Covid-19 and is an important indicator of the severity of COVID-19 [16] [19]. 
Several studies have shown those patients with severe COVID-19 show lower platelet counts than patients with mild COVID-19 [15][20][21][22].

The number of leukocytes or WBC values in 79 respondents $(77.5 \%)$ increased. This indicates the occurrence of leukocytosis. This result is by the systematic review of 48 literature by Chamseddine et al which stated that the most common abnormality was leukocytosis [17]. Pregnant women with or without Covid-19 may experience normal leukocytosis. This occurs because of an increased inflammatory response which is an adaptation of the body's immune system and immunomodulation of the fetus [23].

This research still has several things that can be improved, namely first completing laboratory examinations. The number of different laboratory tests in each patient so that many patients do not meet the inclusion criteria. Second, it is necessary to increase the number of samples used. Third, it is necessary to conduct further research in the form of analytical research to determine the predictor factors of mortality and morbidity so that it can be used as a guide for better patient therapy

\section{Conclution}

The results of this study try to describe the results of laboratory tests, namely the results of blood tests in the 3rd trimester pregnant women with positive RT-PCR test results for Covid-19 who are hospitalized at SMF Obstetrics and Gynecology RSUD Dr. Soetomo, Surabaya, Indonesia. The hematological picture shows a decrease in basophils, eosinophils, lymphocytes or also called lymphopenia. More than half of the normal monocyte, platelet and hemoglobin values, an increase in neutrophils or also called neutrophilia and an increase in the leukocyte count or WBC value indicate leukocytosis. Variations in the results of laboratory parameters require further in-depth research to determine the predictors that significantly affect the mortality and morbidity of COVID19 patients during treatment.

\section{Acknowledgements}

The researcher would like to thank the supervisor who has guided me in this research and the RSUD Dr. Soetomo who has permitted me to conduct research.

\section{References}

[1] P. Zhou et al., "A pneumonia outbreak associated with a new coronavirus of probable bat origin,” Nature, vol. 579, no. 7798, pp. 270-273, 2020, doi: 10.1038/s41586-020-2012-7.

[2] C. Sohrabi et al., "World Health Organization declares global emergency: A review of the 2019 novel coronavirus (COVID19),”Int. J. Surg., vol. 76, pp. 71-76, 2020, doi: 10.1016/j.ijsu.2020.02.034.

[3] WHO, "Beranda|Covid19.go.id," 2021. https://covid19.go.id/ (accessed Jul. 24, 2021).

[4] A. Akbar, "Gejala Klinis Infeksi Virus Corona 2019 (Covid-19) Pada Wanita Hamil,” J. Implementa Husada, vol. 1, no. 2, pp. 172-180, 2020.

[5] N. Breslin et al., "Coronavirus disease 2019 infection among asymptomatic and symptomatic pregnant women: two weeks of confirmed presentations to an affiliated pair of New York City hospitals," Am. J. Obstet. Gynecol. MFM, vol. 2, no. 2, p. 100118, 2020, doi: 10.1016/j.ajogmf.2020.100118.

[6] M. K. Rohmah and A. R. Nurdianto, "Corona virus disease 2019 (COVID-19) in pregnant women and infants: A literature review," vol. 7, pp. 329-336, 2020.

[7] A. Susilo et al., "Coronavirus Disease 2019: Tinjauan Literatur Terkini," J. Penyakit Dalam Indones., vol. 7, no. 1, p. 45, 2020, doi: 10.7454/jpdi.v7i1.415.

[8] B. K. Manne, F. Denorme, E. Middleton, I. Portier, and W. Jesse, "Platelet Gene Expression and Function in COVID-19 Patients Platelet Gene Expression and Function in COVID-19 Patients University of Utah Molecular Medicine Program, Salt 
Lake City , Utah , 84112 Bioinformatics Shared Resource, Huntsman Cancer Institute, , 2021.

[9] S. Sun et al., "Abnormalities of peripheral blood system in patients with COVID-19 in Wenzhou, China," Clin. Chim. Acta, vol. 507, pp. 174-180, 2020, doi: 10.1016/j.cca.2020.04.024.

[10] G. Lippi and M. Plebani, "Laboratory abnormalities in patients with COVID-2019 infection," Clin. Chem. Lab. Med., vol. 58, no. 7, pp. 1131-1134, 2020, doi: 10.1515/cclm-2020-0198.

[11] J. Gao, F. S. J. Soong, Y. F. Low, X. L. Goh, Z. Amin, and Y. P. M. Ng, "Clinical features and outcomes of neonatal COVID19: A systematic review,”J. Clin. Virol., vol. 139, pp. 1-11, 2021, doi: 10.1016/j.jcv.2021.104819.

[12] A. Cavezzi, E. Troiani, and S. Corrao, "COVID-19: Hemoglobin, Iron, and Hypoxia beyond Inflammation. A Narrative Review," Clin. Pract., vol. 10, no. 2, pp. 24-30, 2020, doi: 10.4081/cp.2020.1271.

[13] X. Yang et al., "Clinical course and outcomes of critically ill patients with SARS-CoV-2 pneumonia in Wuhan, China: a singlecentered, retrospective, observational study," Lancet Respir. Med., vol. 8, no. 5, pp. 475-481, 2020, doi: 10.1016/S22132600(20)30079-5

[14] A. Mohr-Sasson et al., "Laboratory characteristics of pregnant compared to non-pregnant women infected with SARS-CoV-2," Arch. Gynecol. Obstet., vol. 302, no. 3, pp. 629-634, 2020, doi: 10.1007/s00404-020-05655-7.

[15] W. Guan et al., "Clinical Characteristics of Coronavirus Disease 2019 in China,” N. Engl. J. Med., vol. 382, no. 18, pp. 17081720, 2020, doi: 10.1056/nejmoa2002032.

[16] D. N. Mutua, E. N. Mwaniki Njagi, and G. Owino Orinda, "Hematological Profile of Normal Pregnant Women,” J. Blood Lymph, vol. 08, no. 02, 2018, doi: 10.4172/2165-7831.1000220.

[17] R. S. Chamseddine, F. Wahbeh, F. Chervenak, L. J. Salomon, B. Ahmed, and A. Rafii, "Pregnancy and Neonatal Outcomes in SARS-CoV-2 Infection: A Systematic Review,"J. Pregnancy, vol. 2020, 2020, doi: 10.1155/2020/4592450.

[18] Kementrian Kesehatan RI, “Pedoman Interpretasi Data Klinik,” Kementeri. Kesehat. Republik Indones., no. January, pp. 1-83, 2011.

[19] J. L. Frater, G. Zini, G. d'Onofrio, and H. J. Rogers, “COVID-19 and the clinical hematology laboratory,” Int. J. Lab. Hematol., vol. 42, no. S1, pp. 11-18, 2020, doi: 10.1111/ijlh.13229.

[20] F. Zhou et al., "Clinical course and risk factors for mortality of adult inpatients with COVID-19 in Wuhan, China: a retrospective cohort study," Lancet, vol. 395, no. 10229, pp. 1054-1062, 2020, doi: 10.1016/S0140-6736(20)30566-3.

[21] C. Huang et al., "Clinical features of patients infected with 2019 novel coronavirus in Wuhan, China," Lancet, vol. 395, no. 10223, pp. 497-506, 2020, doi: 10.1016/S0140-6736(20)30183-5.

[22] W. Liu et al., "Analysis of factors associated with disease outcomes in hospitalized patients with 2019 novel coronavirus disease," Chin. Med. J. (Engl)., vol. 133, no. 9, pp. 1032-1038, 2020, doi: 10.1097/CM9.0000000000000775.

[23] I. O. Osonuga, O. A. Osonuga, A. A. Onadeko, A. Osonuga, and A. A. Osonuga, "Hematological profile of pregnant women in southwest of Nigeria," Asian Pacific J. Trop. Dis., vol. 1, no. 3, pp. 232-234, 2011, doi: 10.1016/S2222-1808(11)60036-4. 